\title{
Professor Shigetaka Asano: extraordinary Japanese Haematologist and Bon Vivant February 7, 1943 to August 12, 2020
}

\author{
Keiya Ozawa ${ }^{1} \cdot$ Hideki Kodo ${ }^{2} \cdot$ Robert Peter Gale $\mathbb{C}^{3}$
}

Received: 24 August 2020 / Revised: 2 September 2020 / Accepted: 9 September 2020 / Published online: 18 September 2020

(c) The Author(s), under exclusive licence to Springer Nature Limited 2020

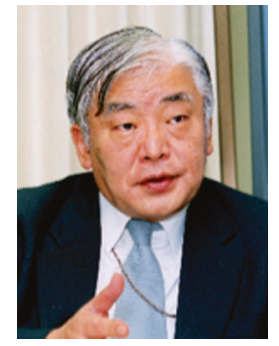

Prof. Shigetaka Asano was born in Yamaguchi prefecture, Japan on 7 February 1943 and died on 12 August 2020, age 77 years. In 1968 he graduated from the Faculty of Medicine, The University of Tokyo. This was an exceptional year. 3 other distinguished Japanese haematologists, Profs. Mine Harada, Masao Tomonaga and Yasuo Ikeda graduated the same year and were friendly lifelong rivals. To appreciate their value consider a 1968 Petrus sells for $€ 3890$. Prof. Asano did his post-graduate training in the 3rd Department of Internal Medicine and earned his Ph.D. from the Faculty of Medicine, The University of Tokyo in 1978. After this he travelled to Australia to study at the Walter and Eliza Hall Institute of Medical Research with Profs. Donald Metcalf, Ian Mackay, and Gustav Nossal where he studied on in vitro growth of cancer infiltrating human T-cells in humans. He returned to Japan as Lecturer (Senior Assistant Professor) of Internal Medicine at the Hospital of the Institute of Medical Science, The University of Tokyo (IMSUT) under Prof. Shiro Miwa in 1980 where he started lifelong projects focused on granulocyte colony-stimulating factor (G-CSF) and haematopoietic cell transplantation.

Robert Peter Gale

robertpetergale@alumni.ucla.edu

1 Jichi Medical University, Tochigi-Ken, Japan

2 Tokyo Cord Blood Bank, Tokyo, Japan

3 Haematology Research Centre, Department of Immunology and Inflammation, Imperial College London, London, UK
Asano-sensei became Associate Professor in 1985 and Professor of the IMSUT in 1990 and Professor of the 4th Department of Internal Medicine, Faculty of Medicine, The University of Tokyo (1992-1994). He served as Director of IMSUT hospital, 1994-2003 and Director of the Advanced Clinical Research Center there, 2001-2004. Asano-sensei retired from IMSUT in 2004 as Professor Emeritus. Always on the go and with unbounded energy in 2004 he moved to Waseda University as Professor of the Faculty of Science and Engineering and Director General of Consolidated Research Institute for Advanced Science and Medical Care, 2010-2012, retiring as Distinguished Guest Research Professor and Emeritus Professor in 2013. He also served as Visiting Professor at the Kobe University Graduate School of Medicine, 2008-2020. RPG 1st met Prof. Asano at UCLA in 1982 when he visited Japanese colleague Hideki Kodo then doing post-doctoral study in RPG's Lab at UCLA.

Prof. Asano had diverse scientific and clinical interests and made untold contributions. He took special pride in the molecular cloning of G-CSF with Prof. Shigekazu Nagata and Chugai Pharmaceutical Co., Ltd. using G-CSFproducing cancers and developing a recombinant human native G-CSF (lenograstim) with Chugai for extensive clinical applications which is used widely in Asia. He also developed a haematopoietic cell transplant programme at the IMSUT hospital with a special focus on umbilical cord blood cell transplants and where RPG worked with him in 1999 after the Tokaimura Nuclear Processing Plant Accident near Tokyo. Prof. Asano helped create the Japan Marrow Donor Program and the Public Cord Blood Banking system in Japan. He was also deeply involved in gene therapy research, particularly for cancer gene therapy. In 1995 he established the Japan Society of Gene Therapy. One of his great achievements was uniting the Japanese Society of Haematology and Japanese Society of Clinical Haematology in 2008.

Prof. Asano was a member of the so-called IMSUT ANA trio along with Profs. Yusuke Nakamura and Ken-ichi Arai. 
The trio was a major driving force in Japanese medical science with worldwide recognition in diverse fields including cytokine and cytokine receptor research and human genome sequencing.

In another collaboration with Asano-sensei immediately after the Fukushima-Daiichi Nuclear Power Plant Accident in March, 2011, he and RPG travelled to the destroyed facility to survey the damage and work with medical colleagues. It was a quick trip; everyone was going in the opposite direction on the highway. He was unafraid of radiation but insisted we stop every hour for a smoke. In 2011 he became Director of Institute for Research on Reconstruction from the Great East Japan Earthquake/ Advanced Institute for Environmental Science and Medical Engineering at Waseda University.

Prof. Asano was a member of many academic societies including the Japanese Society of Hematology, Japan Society for Hematopoietic Cell Transplantation, Japan Society of Gene and Cell Therapy, Japanese Cancer Association, Japanese Society of Inflammation and Regeneration, Japanese Society of Internal Medicine and Science Council of Japan. He was Honorary Professor, Institute of Hematology and Blood Diseases Hospital, Chinese Academy of Medical Sciences \& Peking Union Medical College in Tianjin, China and Honorary Professor, Peking University Health Science Center in Beijing, China.

Prof. Asano received many awards, including Erwin von Bälz Prize (1990), Nikkei BP Technology Prize (1993), Award of Molecular Biology of Hematopoiesis (2000), Commendation for Science and Technology from the Ministry of Education, Culture, Sports, Science and Technology (2004), Okuma Academic Commemorative Prize from Waseda University (2012), JCA-CHAAO Award (2017) and The Order of the Sacred Treasure, Gold Rays with Rosette (2017). (For those unfamiliar The Order of the Sacred Treasure (瑞宝章, Zuiho-shō) is a Japanese order and honour established in 1888 by the Emperor Meiji).

In addition to these extraordinary scientific and medical accomplishments Prof. Asano was a bon vivant. A lifetime heavy smoker (he quit at least 10 times that RPG recalls) and enthusiastic drinker, he loved to take RPG to small jazz clubs in Chiyoda-ku near the Imperial Hotel when RPG was living in Tokyo after the Fukushima accident. He was a regular at about 10 jazz private clubs where at each he customarily kept a bottle of excellent Japanese whiskey. Our starting plan was to visit 3 or 4 clubs a night spending about an hour at each. RPG often collapsed after 2 or 3 but Asano-sensei persevered exiting to the kilometre long taxi que outside Teikoku (Imperial Hotel) at $2330 \mathrm{~h}$, late for Japan. God knows what he paid the driver to take him home. (Metered fares are usually increased at this hour which is why foreigners [外国人; Gaikoku-Jin] have no chance to get a taxi after $2200 \mathrm{~h}$ ).

KO worked at the IMSUT 1987-1994 where he learned much from Asano-sensei about advanced medicine. An experience unachievable at any other Japanese University Hospital at that time. Asano-sensei was always very busy with off-campus dinner meetings often returning to his Institute office near midnight. On encountering $\mathrm{KO}$ he would break into an impassioned, often incomprehensible, endless speech. Because the Tokyo subway closes at midnight KO always tried to leave the Institute before Asano-sensei's post-prandial return and lecture. God knows what time Asano-sensei went home or if he went home.

Prof. Asano left an indelible mark on Japanese haematology and haematopoietic cell transplantation. This is only a partial summary of his remarkable accomplishments. He is survived by his wife Kazuko, 4 sons and many grandchildren. Japanese haematology will never be the same. Nor will the Chiyoda-ku jazz clubs.

Acknowledgements Profs. Satoshi Takahashi and Arinobu Tojo (IMSUT) kindly reviewed the typescript. RPG acknowledges support from the National Institute of Health Research (NIHR) Biomedical Research Centre funding scheme.

Conflict of interest The authors declare that they have no conflict of interest.

Publisher's note Springer Nature remains neutral with regard to jurisdictional claims in published maps and institutional affiliations. 